\title{
Concept of green highway and practice of green highway in Jiangxi Province
}

\author{
Jun $\mathrm{Liu}^{1,2}$, Wensheng $\mathrm{Yu}^{2}$, Xianjie Weng ${ }^{3}$, Zichuan $\mathrm{Han}^{4}$ \\ ${ }^{1}$ School of civil engineering, Shandong University, Jinan, Shandong, 2500061, China \\ ${ }^{2}$ Jiangxi provincial expressway investment Group Co., Ltd, Nanchang, Jiangxi, 330000, China \\ ${ }^{3}$ Jiangxi traffic consulting company, Nanchang, Jiangxi, 330008, China \\ ${ }^{4}$ College of pipeline and civil engineering, China University of Petroleum, Qingdao, Shandong, 266580, China
}

\begin{abstract}
Ecological civilization construction has become an important part of national development. We must establish and practice the idea that clear water and green mountains are mountains of gold and silver, adhere to the basic state policy of resource conservation and environmental protection, form a green way of development and a way of life, firmly follow the path of civilized development with production development, a prosperous life and a sound ecology, and build a beautiful China. This article introduces the practice of green highway construction in Jiangxi Province from the connotation of green highway, promotion of green technology application, green construction technology and innovative management. Finally, the future development direction of green highway in Jiangxi province is prospected.
\end{abstract}

\section{Introduction}

We must adhere to the basic national policy of conserving resources and protecting the environment, form a green development model and a way of life, and firmly follow the path of civilized development featuring increased production, prosperous living and sound ecology, so as to build a beautiful China. Therefore, promoting green highway construction is an inevitable choice for the highway industry to practice the five development concepts and adapt to the development transformation and upgrading in the new era. A large number of scholars have carried out relevant studies on green highway. Wei Chungen[1], Chen Xueping[2] and others have conducted a detailed study on the evaluation index system of green highway maintenance. Huang Xuewen[3] introduced the practice of green highway exploration and the construction concept of green Bridges in Anhui Province. Zhang Yuan[4] sorted out the compliance and application of the green and low-carbon concept of New Zealand green highway in laws and regulations, construction standards, planning and design, etc. Zhang Zhe[5] introduced the application practice of green highway design concept in urban road design based on the reconstruction project of Huizhou Airport Expressway. Li Gang[6] introduced the application of the concept of green highway in the interprovincial passageway of Inner Mongolia. He Yajun[7] introduced the application practice of green highway concept in the design of Dechang-Huili Expressway.

\section{Connotation of green highway}

The understanding of green highway and its connotation is deepening in the practice of highway construction.

\subsection{Green highway stage of ecological environmental protection}

With the new concept of "six insistences and six establishments" as the symbol, Jiangxi province takes the first batch of typical expressway projects of survey and design - Jingdezhen-Wuyuan-Baishaguan Expressway as the benchmark, and promotes shallow dish-shaped ditch, circular slopes, New Jersey crash barrier etc, increase plant protection. In addition, it is necessary to eliminate unnecessary hard protection, strengthen environmental protection and ecological landscape design, and change the way of uncoordinated with the surrounding natural environment by splitting hard blasting and large-scale sewage masonry, so as to integrate the expressway into the surrounding environment.

\subsection{Green highway stage of low carbon, energy saving and safe}

Mainly marked by the requirements of "resource-saving and environment-friendly" and the "five modernizations" concept of highway construction and management, the connotation of green highway is further integrated into energy-saving and emission reduction, low-carbon design, resource recycling, safety quality, ETC and other intelligent transportation, green energy applications etc, 
and the green highway begins to develop in the whole process and all-round direction of highway construction. The main representative projects in Jiangxi province include Yongxiu-Wuning Expressway and its Xihai service area which won the Science and Technology Demonstration Project of the Ministry of Transport, the Second Jiujiang Bridge which won Zhan Tianyou, Luban and National Quality Project Awards, NanchangZhangshu Expressway reconstruction and extension project which won green highway demonstration project of Ministry of transport, Ningdu-Dingnan Expressway which won smart transportation technology demonstration project of Ministry of transport and other projects

\subsection{Green highway stage of full life cycle and satisfying beautiful travel}

With the deepening of the new national environmental protection policy and the introduction of the guiding opinions on green highway Construction issued by the Ministry of transport in 2016, the connotation of green highway construction has been continuously expanded and upgraded. While the Ministry of transport proposed the construction of green highway, new requirements were put forward, such as promoting steel structure bridge, BIM Technology Application, quality engineering, intelligent transportation, ecological civilization construction, integration of tourism and transportation.

This is the enrichment and extension of the connotation of green highway. The representative projects include the Ganwan-Wuyuan section of the national highway network De-shang Expressway and the follow-up construction projects. The green highway construction pays more attention to sustainable development, expands service upgrading, coordinates life cycle management, and coordinates people, vehicles, roads and environment to meet people's demand for better travel.

\section{Practice of green highway in Jiangxi Province}

\subsection{General situation of green highway}

The total mileage of expressways in Jiangxi Province is $6400 \mathrm{~km}$, and the green construction of expressway has been actively carried out in Jiangxi Province. Our province has issued the Work Plan for Promoting green highway Construction in The Whole Province, which has deeply integrated the green highway construction with quality engineering, standardized construction, steel structure bridge promotion and application. This has formed a number of green highway typical demonstration mainly represented by highway projects, giving full play to the demonstration role of demonstration projects, promoting the application of good experience and technology in green highway construction which is widely used in the whole province. Our province has established three guiding mechanisms for pre-project review, assessment and evaluation during project construction, and rewards. The system ensures that the concept of green highway is implemented in all stages of highway project construction. Jiangxi Province studies and formulates three technical standards with Jiangxi characteristics: Technical Guide for green highway Construction in Jiangxi Province, Guide for green highway Construction Management in Jiangxi Province, Comprehensive Evaluation Standard for green highway in Jiangxi Province, so as to lay a solid technical foundation for comprehensive development of green highway construction.

\subsection{Promotion of application of green energy and building materials}

According to the trend of national industrial policy and the demand of green highway construction, Jiangxi Province actively promotes the deployment of green and renewable clean energy, along the highway, such as photovoltaic power generation, charging piles etc, and actively promotes the application of environmentally friendly materials and the reuse of waste materials in highway construction and maintenance projects. These measures have effectively reduced social resource occupation and pollution emissions

\subsubsection{Large-scale application of photovoltaic power generation}

The distributed photovoltaic power generation project of Jiangxi Expressway is planned to be $100 \mathrm{MW}$, with a total investment of about 820 million yuan. Currently, $12.8 \mathrm{MW}$ photovoltaic power generation projects have been installed in 85 toll stations (stations), 47 pairs of service areas, such as roofs, green spaces, slopes, parking sheds etc. In 2017, the total power generation reached 10.4 million $\mathrm{KWh}$, the profit was 3.44 million yuan, and the return on investment was $6.89 \%$. 


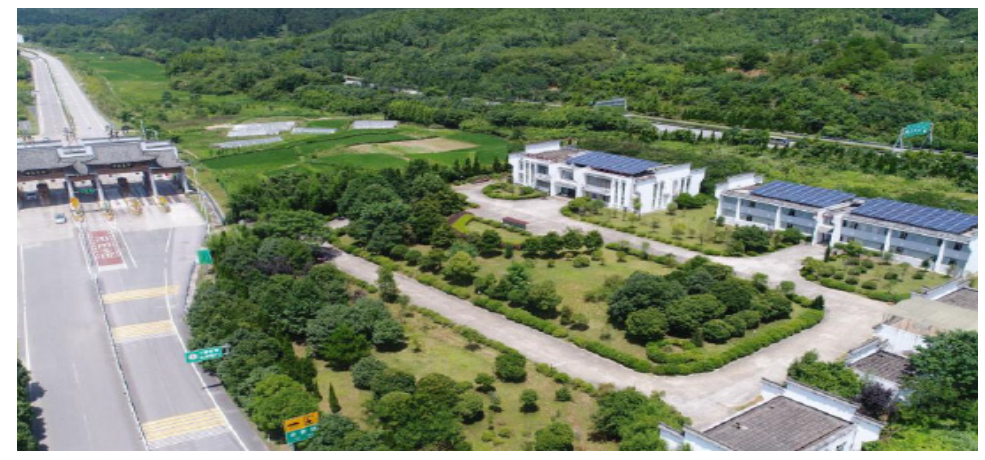

Figure 1. Photovoltaic power generation of toll station

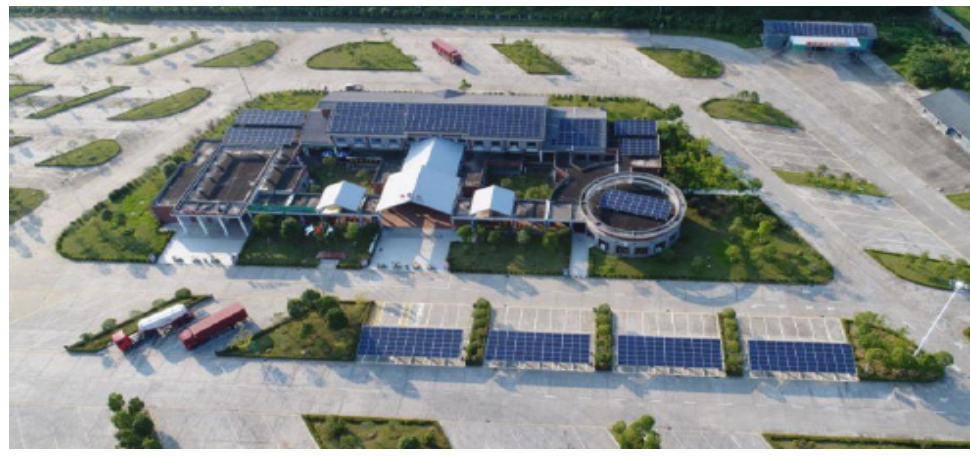

Figure 2. Photovoltaic power generation in service area

\subsubsection{Construction of LNG gas station and service area covering charging pile}

A pair of LNG gas stations are planned for every 150$200 \mathrm{~km}$ along the expressway. A total of $60 \mathrm{LNG}$ gas stations are planned and constructed in the service area in three years. The construction of the first batch of LNG gas stations in Lushan, Longhushan, Nancheng and Jian service areas is gradually started. Provincial Expressway Group and electric power company cooperate to carry out charging station business in expressway service area. At present, the fast charging stations along the national expressway networks of Daqing-Guangzhou, FuzhouYinchuan, Hangzhou-Ruili, Shanghai-Kunming, JinanGuangzhou have been set up in the service areas, in the whole province, with a total of 94 charging stations. Basically the network of fast charging stations in expressway service areas covering the whole province has been formed.

\subsubsection{Promote the application of rubber asphalt}

Starting from the Jingdezhen-Yingtan Expressway in 2006 , the $2 \mathrm{~km}$ rubber asphalt test section was launched. Currently, about $70 \mathrm{~km}$ of the Guangchang-Jian Expressway under-construction is planned to use rubber powder composite modified asphalt pavement technology for the upper and lower layers, which is expected to consume waste tire rubber powder. It is estimated that about 4000 tons of waste tire rubber powder will be consumed and about 140000 large truck tires will be recycled.

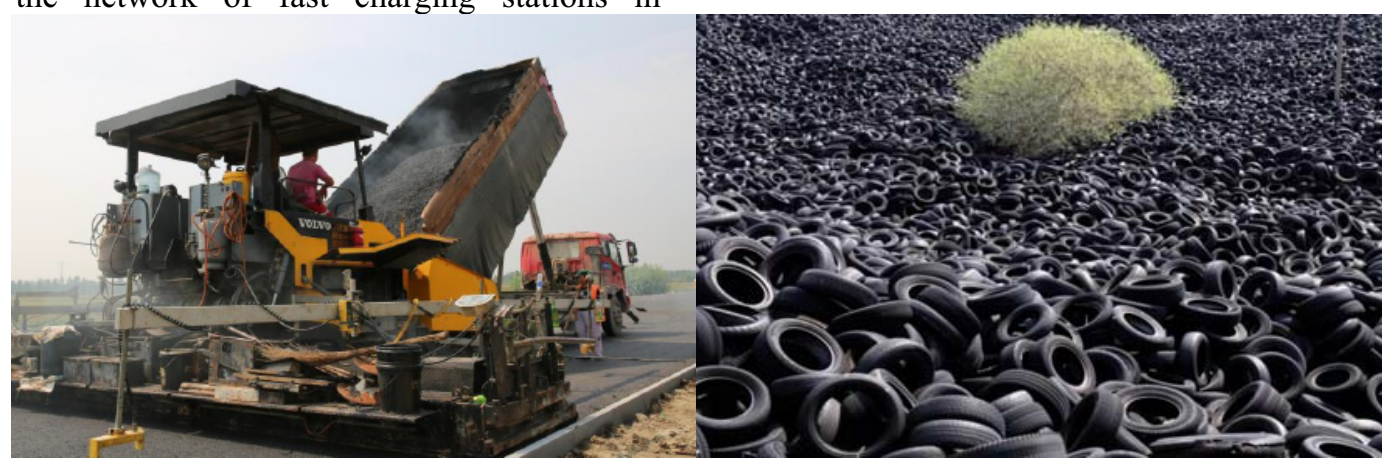

Figure 3. 70 kilometers of Guangchang-Jian Expressway project adopts double-layer rubber powder composite modified asphalt pavement 


\subsubsection{Full use of waste materials}

The first Nanchang-Zhangshu Expressway reconstruction and expansion project that opened to traffic: useing about 500000 tons of plant mixed cold recycled mixture, saving about 6600 tons of standard coal and reducing carbon dioxide emissions by about 17,000 cubic meters. The "oil to gas" technology of asphalt mixing plant was adopted in the whole line, which reduced the carbon dioxide emission by more than 30000 tons; the reuse technology of traffic facilities was adopted; the old isolation fence was reused about $41.9 \mathrm{~km}$, and more than 100 sets of original signboards were reused.
The reconstruction and extension project of Nanchang-Jiujiang Expressway: the utilization rate of milling material for old road reaches $100 \%$, and the utilization of cold recycled mixture is about $100000 \mathrm{~m} 3$ which saving 2961 tons of standard coal, reducing 7760 tons of carbon dioxide emission and saving about 347 mu of land. In addition, the reuse of the New Jersey wall in the old central separation zone saved 2975 tons of steel that equivalent to 2083 tons of standard coal, and reduced carbon dioxide emissions by 5456 tons. The waste slag from urban construction is used for subgrade filling, improvement and utilization of 490000 cubic meters of high liquid limit soil along the line.

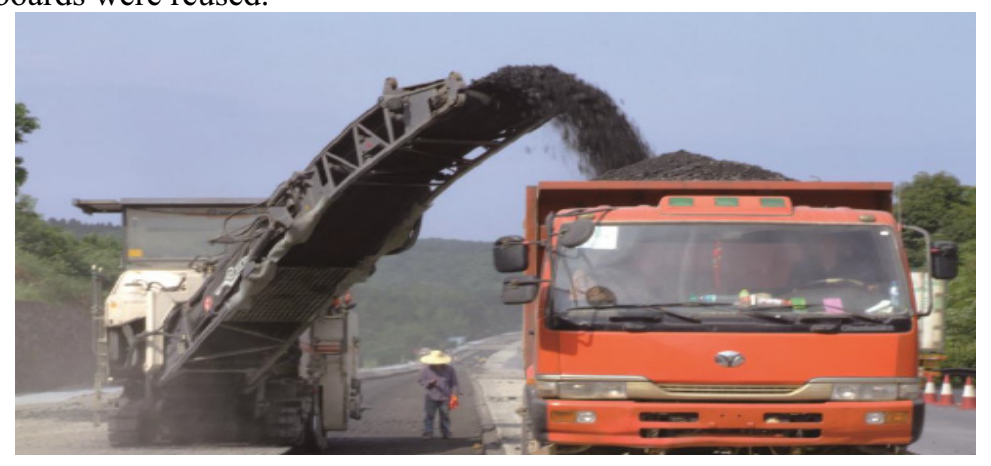

Figure 4. Reuse of milling materials in Nanchang-Jiujiang reconstruction and extension project

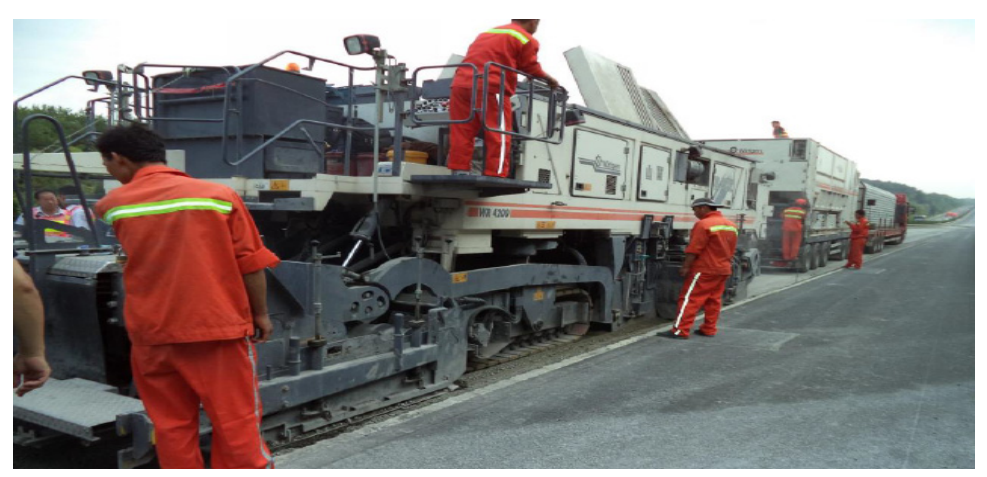

Figure 5. Local cold regeneration of Provincial Expressway Group

\subsection{Green low-carbon design}

The concept of green highway is integrated into all stages of road construction such as design, construction, operation and maintenance, to realize ecological route selection, and to practice new green technologies such as assembled bridges and steel-concrete composite bridges. Green construction technologies such as normalized construction, mechanized operation, intensive production and preventive maintenance should be promoted.

\subsubsection{Green low-carbon design}

During the three reconstruction and expansion projects, including Nanchang-Jiujiang reconstruction and expansion project and Nanchang-Zhangshu reconstruction and expansion project, the traffic organization scheme of "construction in different sections and four lanes to ensure traffic" was adopted, which significantly reduced vehicle fuel consumption and carbon emission. According to the calculation, the $\mathrm{CO} 2$ emission can be reduced by 710500 tons, equivalent to 264400 tons of standard coal.

In the highway design stage, it is suitable for the local conditions, and flexible design is made. In the route selection stage, the Cultivated Land is reasonably avoided. The high excavation and high filling are reduced. The filling and excavation balance in the bid section; the local materials are used. The tunnel slag is used as much as possible. The tunnel ventilation control, intelligent lighting control and tunnel traffic control and other intelligent control technology are promoted. For example, through the optimization in the design stage of Guang-Ji project, the land use is reduced by $1600 \mathrm{mu}$, and the earthwork are reduced 3.7 million cubic meters. 


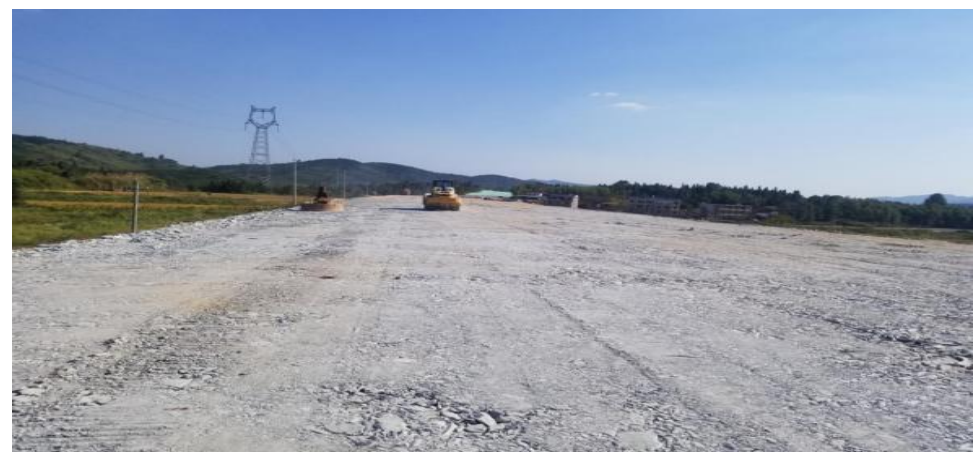

Figure 6. Application of tunnel slag in Pingxiang-Lianhua Expressway to roadbed

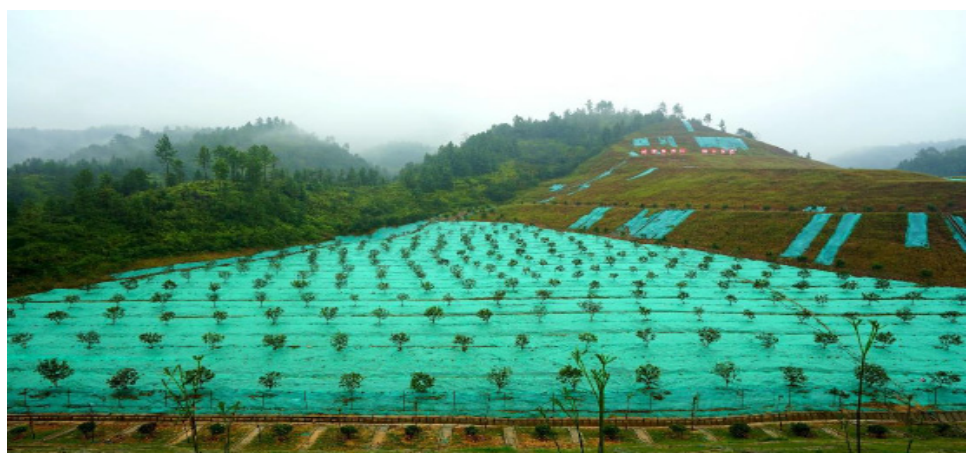

Figure 7. Guangji Expressway spoil ground restored to Bayberry Garden

\subsubsection{Industrial construction technology of bridge and culvert}

Promotion of steel-concrete composite beam: based on the "5511" major research and development project in Jiangxi Province, we have carried out the key technology research on the industrialized construction of prefabricated steel-concrete composite beam bridge, and have carried out the steel-concrete composite beam bridge in 11 bridges with $4280 \mathrm{~m}$ and standard span of 30-60 $\mathrm{m}$ in 4 expressway projects including Guangchang-Jian, Fuzhou east outer ring, Yifeng connecting line and Pingxiang-Lianhua.
Bridge and culvert assembly practice: NanchangJiujiang reconstruction and expansion project creates a $300 \mathrm{mu}$ large-scale construction and manufacturing center, producing $72 \%$ beam slab, $84 \%$ culvert and $100 \%$ small components of the whole project, saving more than $200 \mathrm{mu}$ of temporary land, more than 500 human resources and more than 38 million yuan of cost. In addition, the prefabrication and assembly technology of bridge pier, abutment and bridge deck system are explored and practiced in the two branch line overpass bridges in Wuchang village and Qiaonan village.

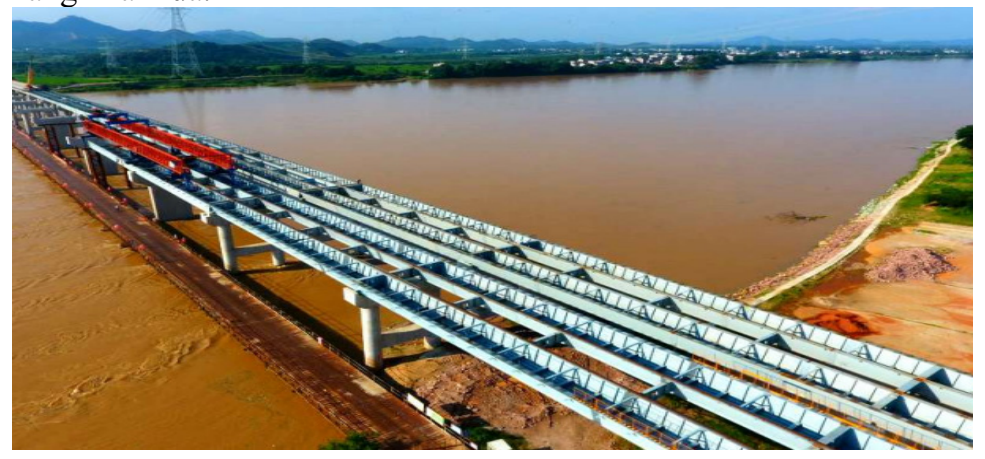

Figure 8. Construction of outer steel beam in Fuzhou east outer ring 


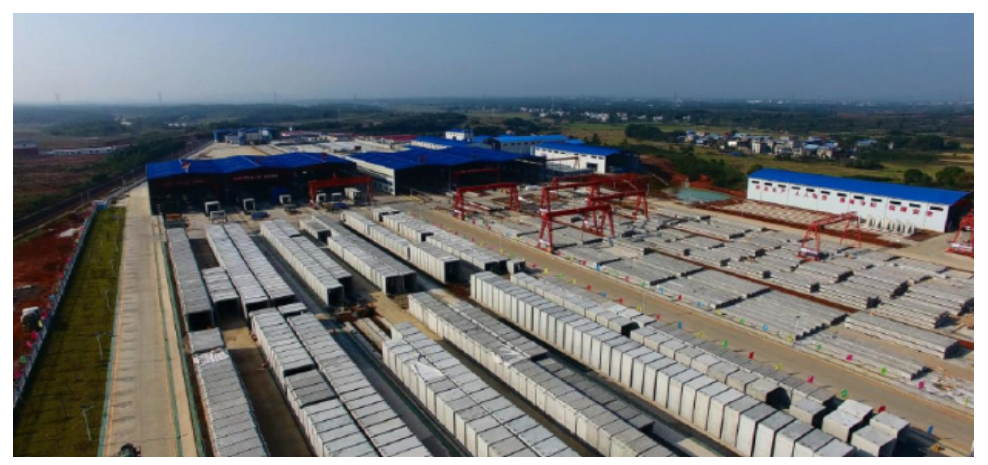

Figure 9. Large scale construction manufacturing center of Nanchang-Jiujiang reconstruction and expansion project

\subsubsection{Intensive resource saving}

The highway facilities are arranged in a centralized way. The temporary facilities such as construction road, resident sites and power consumption are combined permanently and temporarily, and the prefabricated yard and mixing station are centralized. For example, in principle, each bid section of the expressway is allowed to set up only one large prefabricated yard, one reinforced shed, one concrete mixing station, and one small component prefabricated yard, so as to realize the intensification of stations and reduce the number of temporary land use and pollution sources. Large scale prefabrication yard and steel shed are encouraged to be set in the main line, service area or station, so as to reduce the temporary land use. Through this measure, Guangchang-Jian project can save more than $1000 \mathrm{mu}$ of temporary land acquisition. The combination of permanent and temporary power supply for tunnel construction is realized.

In the construction, nine sets of equipment such as multi arm rock drill, wet spraying manipulator, selfpropelled mobile trestle and multi-functional trolley are widely used to realize the mechanization of tunnel construction.

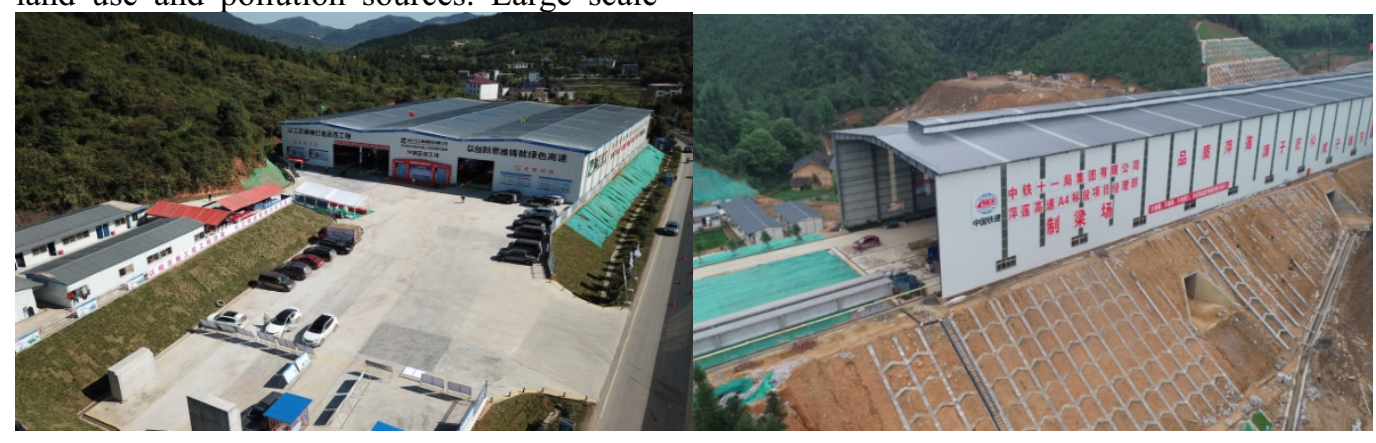

Figure 10. Large scale Prefabrication Yard and Beam Yard of Pingxiang-Lianhua Expressway project under construction in Jiangxi Province(Set on Subgrade)

\subsubsection{Strict control of pollution discharge.}

Adopting energy-saving technology, the black station of asphalt concrete has promoted the "oil-to-gas conversion". Since 2006, the warm mixing technology has been fully implemented in the asphalt pavement paving of long highway tunnels to improve the construction environment. As for sewage treatment, we will centralize the sewage treatment, standardize the discharge of station and construction sewage. In addition, the mud for bridge construction on important rivers such as Poyang Lake is centralized and put ashore for disposal. Regarding the control of construction dust, our province is responsible for the prevention and control of construction dust, and increases the investment of dust control equipment and personnel. The spray dust control machine is equipped in the more serious location of the dust field in the precast field, reinforced bar and tunnel, and equipped with PM2.5 testing equipment. After the standard exceed the standard, the spray dust is automatically started, and the environment along the expressway construction is improved.

\subsection{Innovation management promotes green construction of green highways}

Our province is deeply advancing the reform and innovation of highway construction management system, and implementing new project management models such as general contracting for design and construction, general contracting for design, construction and maintenance, etc. In addition, electronic bidding, material centralized purchasing, intelligent charging and intelligent high-speed operation management are implemented to effectively improve the efficiency of green high-speed management. 


\subsubsection{Fully implementing electronic bidding}

In the field of highway engineering construction bidding, Jiangxi province takes the lead in carrying out electronic bidding for highway engineering, conducting online transactions throughout the whole process to improve the efficiency of bidding and reduce transaction costs. At present, electronic bidding has covered the main highway engineering and all ancillary projects horizontally, and has been vertically distributed to the provincial, municipal and county level public resource trading centers. At present, more than 1,000 projects have been conducted electronic bidding through transportation platforms, and the transaction amount has exceeded 100 billion yuan. It is estimated that in recent years, the electronic bidding for 32 expressway projects has saved the tenderer and bidder more than 10 million yuan in direct costs

\subsubsection{Practice intelligent operation management}

In terms of intelligent toll collection system management, $100 \%$ coverage has been achieved in 337 toll stations ETC and unattended automatic card issuing machines on expressways in the province, and mobile code scanning payment systems have been basically installed. Jiangxi province has been identified by the Ministry of Transport as a pilot province for smart highway, new generation of national traffic control network and big data application of traffic and tourism service. The Ningdu-Dingnan Project has built the first smart highway in the province, which is included in the first batch of smart high-speed science and technology demonstration projects of the Ministry, effectively improving the user experience of public travel.

\section{$4 \quad$ Prospect of green highway in Jiangxi Province}

\subsection{Creation of green and smart expressway demonstration project}

The proposed Jiangxi-Anhui Junction to Wuyuan project starts from the top-level design, comprehensively increases collaborative innovation in the design stage, deeply explores the construction of green expressway, and uses BIM Technology platform to coordinate new technologies such as ecological landscape, industrial construction, transportation, tourism and intelligent transportation. The project implements the concept of green highway construction, pilot BIM positive design, carries out the industrial construction of steel-concrete composite beam, creates a new open service area, integration of auxiliary road and county rural highway, creates seamless connection of two highway traffic systems with fast forward and slow travel and application of intelligent and safe traffic technology etc, to build a green expressway with new era characteristics

\subsection{Exploration of transportation and tourism and comprehensive planning, explanation of service function of highway}

Integrate expressway toll fast lanes, ordinary national and provincial roads and rural roads, It is necessary to build a comprehensive highway transportation system with fast forward and slow travel, expand the function of service area, and increase the functions of Self-driving caravan camping base, tourism distribution center and comprehensive passenger service base. When conditions are met, it can be built with ordinary roads to create an open service area and drive regional tourism.

\subsection{Creation of smart transportation quality project, service of people's better travel needs}

We plan to cover all of the province's 6000 kilometers of expressways with one high-definition camera per kilometer, and provide power throughout the entire process. Key road sections and important facilities are embedded and installed with road sensing systems. Then, through a large traffic management platform, the highway traffic can be visualized, measurable, and controllable, deepen the research of vehicle-road collaborative technology, and improve the service function of the road network. The "Beidou free-flow tolling technology application and demonstration test work" was jointly carried out with the Communications and Information Center of the Ministry of Communications, and it has been verified in the complex environment of Nanchang ring expressway. It serves as a technical reserve for the full cancellation of checkpoint toll stations in the future to truly realize free flow toll; Coordinating the two road transportation systems, strengthening research on life-cycle costs, effectively improving project quality and safety, and adhering to the people-centered concept of harmonious coexistence between man and nature, and better serving the people's needs for better travel.

\section{Conclusion}

The environment is people's livelihood, green mountains are beauty, blue skies are happiness. We must try our best to protect the environment, just like the way we protect our eyes, and treat it like we treat our lives. On the basis of satisfying the basic needs of highway traffic, the project quality should be improved, the service function of expressway should be expanded, regional cultural characteristics and resource characteristics should be integrated, and local targeted poverty alleviation and tourism resource development should be assisted. We should coordinate the coordination of people, vehicles, roads, environment and society and the cost of the whole life cycle, solve the good way and the nature harmonious coexistence, let the castle peak green water, beautiful landscape of ecological civilization construction can further spreading in China, and pave green highway to meet people's increasing green beautiful ecological environment and good travel needs. 


\section{References}

1. Wei,C.G., Yu,S.J., Zhang,P. (2020)Research on evaluation index system of green highway maintenance. Highway Traffic Technology (Applied Technology Edition)., 15(07): 325-329.

2. Chen,X.P., Bai,S.H., Yao,J.L., etal. (2020)Green highway Evaluation Index System and Its Evaluation Method. Transport Research., 6(04): 917.

3. Huang,X.W. (2019)Practice green highway and boost high quality development. China Highway., 8(15): 26-27.

4. Zhang,Y., Huang,Q.S. (2019)Practice characteristics of green highway in New Zealand and Its Enlightenment to China. Transport Construction \& Management., 26(04): 84-89.

5. Zhang,Z. (2020)Application of green highway design concept in urban road design. Anhui Architecture., 27(09): 183-184.

6. Li,G. (2019)The Application of Green highway Concept in Inter-provincial Passage in Inner Mongolia. Shanxi Science \& Technology of Communications., 26(04): 103-105.Thompson, J.N. (1984) Insect Diversity and the Trophic Structure of Communities. In: Ecological Entomology. New York. pp. 165-178.

7. He,Y.J., Liu,Y.X., Fang,Z., Cheng,J.Y. (2020)Application and Practice of Green highway Concept in the Design of Dehui Expressway. Construction \& Design for Engineering., 45(19): 128-130. 